\title{
Student Perspective on Defining Engineering Leadership
}

\section{Robyn Paul, University of Calgary}

Robyn is a Master of Science candidate in Civil Engineering at the Schulich School of Engineering, University of Calgary. Her research focuses on the impact that teaching engineers leadership has on early career success. She co-founded the Engineering Education Students' Society and is involved with initiatives to collaborate nationally to increase the conversation with students about engineering education.

Dr. Lynne Gradon Cowe Falls P.Eng., University of Calgary 


\title{
Student Perspective on Defining Engineering Leadership
}

\begin{abstract}
Many definitions and theories of leadership that have evolved over the past few centuries. However, only recently has the term engineering leadership been introduced and there is a lack of a clear definition. A stronger understanding of the different perspectives of this term will help institutions to develop and improve engineering leadership education programs. The aim of this research project is to answer the following: from the perspective of engineering students, academics, and professionals, what is engineering leadership and what skills are required to be a leader in engineering? This paper provides a summary of the results from a pilot study conducted with a group of undergraduate students. Engineering students were surveyed to understand their perspective on engineering leadership as well as a self-evaluation of their own leadership skills. The engineering leadership definition responses were analyzed using qualitative content analysis. Three main themes of engineering leadership were generated: Strong Character, Team Dynamics and Technical, and each of these three broad areas were equally emphasized by the students. The determined themes and the more detailed categories of engineering leadership could be used to develop and improve engineering leadership education programs. The self-evaluation results emphasized the need to teach leadership within an integrated learning experience, to help students have more confidence in the technical application of their leadership skills.
\end{abstract}

\section{Introduction}

Engineers are no longer only involved with the technical project details, but must also understand the broader picture as they are often acting as team leaders ${ }^{1}$. Consequently, there is a need to educate engineers not just in physics and mathematics, but also in many nontechnical areas, including globalization, communication, and leadership ${ }^{2}$. One of the difficulties in the field of engineering leadership education is the need to clearly define the term engineering leadership ${ }^{3}$. A stronger understanding of this term will help institutions to develop and improve engineering leadership education programs.

The aim of this research is to determine from the perspective of engineering students, academics, and professionals, what is engineering leadership and what skills are required to be a leader in engineering? This paper provides a summary of the results from a pilot study that was conducted with a group of undergraduate students. To begin, current engineering leadership research and definitions will be discussed.

\section{Engineering Leadership Literature}

Leadership has been studied by thousands and there have been hundreds of definitions of leadership, yet leadership is still one of the least understood concept ${ }^{4}$. Due to the complex and specialized nature of engineering, it is important to gain an understanding of leadership specifically within an engineering context ${ }^{5}$. Over the last decade there has been an increase in 
the amount of research on engineering leadership. The following focuses on definitions provided by three well-known organizations.

The Bernard M. Gordon-MIT Engineering Leadership Program (GEL) provides a simple definition of engineering leadership as being "the technical leadership of change" including the innovation, implementation and invention of products and enabling technologies to meet the needs of society ${ }^{6}$.

In 2010, the National Society of Professional Engineers (NSPE) outlined the need for preparing students for the professional engineering practice by providing them with the "ability to apply principles of leadership"" . The NSPE provided the following definition that defines engineering leadership through a list of required capabilities:

"the ability to assess risk and take initiative, the willingness to make decisions in the face of uncertainty, a sense of urgency and the will to deliver on time in the face of constraints or obstacles, resourcefulness and flexibility, trust and loyalty in a team setting, and the ability to relate to others" $"$ (p.1).

Lastly, the CDIO Syllabus, an internationally recognized innovative engineering education framework, recently added an extension to include leadership. Within the extension, it is clearly stated that leadership is not orthogonal to the remainder of the engineering curriculum, but rather there is an extensive amount of overlap between leadership skills and the other engineering skills ${ }^{8}$. CDIO defines engineering leadership as "the role of helping to organize effort, create vision, and facilitate the work of others" $"$ (p.68). It is specified that within an engineering context the approaches to leadership that tend to provide the best fit are those that focus on an environment of "change, uncertainty, and the deliberate pursuit of invention"5.

Overall, these definitions provide three different viewpoints that give a basic understanding of leadership within an engineering context. They will be used as the basis as a comparison for the findings of the study.

\section{Population Surveyed}

Surveys for the pilot study were distributed at a student leadership conference at the Schulich School of Engineering in fall of 2014 and participation in the survey was optional. Of the 50 conference attendees, 37 students returned the questionnaire with 28 students completing the full survey. This was an acceptable number of participants in order to analyze the data since for research in grounded theory John Creswell ${ }^{9}$ recommends about 30 participants. When the pilot study is expanded it will be necessary to collect more data such that accurate comparisons can be made when the participants are grouped based on demographics.

A summary of the participant demographics can be seen in Table 1. Although ethnical background data was not collected, it is worthwhile to mention that a high percentage of the participants (close to half) were from minority ethnic groups including Asia and the Middle East, but almost all North American born. 
Table 1. Summary of participant demographics.

\begin{tabular}{|c|l|c|c|c|c|}
\cline { 3 - 5 } \multicolumn{2}{c|}{} & \multicolumn{2}{c|}{$\begin{array}{c}\text { Participated in Skills } \\
\text { Survey }(\mathrm{n}=37)\end{array}$} & \multicolumn{2}{c|}{$\begin{array}{c}\text { Provided EngLead } \\
\text { Definition }(\mathrm{n}=28)\end{array}$} \\
\cline { 3 - 6 } \multicolumn{2}{c|}{} & $\mathrm{n}$ & $\%$ & $\mathrm{n}$ & $\%$ \\
\hline \multirow{3}{*}{\begin{tabular}{c} 
Year of Study \\
\cline { 2 - 6 }
\end{tabular}} & First & 4 & $11 \%$ & 4 & $14 \%$ \\
\cline { 2 - 6 } & Second & 7 & $19 \%$ & 6 & $21 \%$ \\
\cline { 2 - 6 } & Third & 15 & $41 \%$ & 11 & $39 \%$ \\
\cline { 2 - 6 } & Fourth+ & 10 & $27 \%$ & 7 & $25 \%$ \\
\cline { 2 - 6 } & Blank & 1 & $3 \%$ & 0 & $0 \%$ \\
\hline \multirow{2}{*}{ Gender } & Female & 23 & $62 \%$ & 20 & $71 \%$ \\
\cline { 2 - 6 } & Male & 14 & $38 \%$ & 8 & $29 \%$ \\
\hline \multirow{2}{*}{$\begin{array}{c}\text { Previous Conference } \\
\text { Attendee }\end{array}$} & Yes & 13 & $35 \%$ & 12 & $43 \%$ \\
\cline { 2 - 6 } & No & 24 & $65 \%$ & 16 & $57 \%$ \\
\hline
\end{tabular}

All participants completed the skills questionnaire $(n=37)$, however nine of the participants opted to not provide a definition of engineering leadership. Relatively, a higher percentage of females, first year students, and previous conference attendees completed the full survey. It should be noted that the participants were attendees of a leadership conference, thus they likely had previous knowledge of leadership or an interest in leadership. This population may skew the data, however the methodology and results used will be valuable as this is intended to be a pilot study.

\section{Survey Content}

Engineering Leadership Definition. The first part of the survey included an open-ended question: How would you define the term "leadership" in an engineering context? This style of question was chosen in order to give the participants flexibility in their answers. A conscious decision was made to place it first on the survey in order to minimize the bias of the participants obtaining ideas from the items in skills questionnaire.

Self-Rating of Engineering Leadership Skills. The second part of the survey included a skills questionnaire that was developed based on the survey instrument created by Ahn et al. ${ }^{3}$. Ahn et al.'s survey contained 45 items specifically designed to measure outcomes in engineering undergraduate students related to leadership, adaptability to change, and synthesis abilities ${ }^{3}$. Twenty of these items, principally the ones directly related to leadership, were chosen for the skills questionnaire (e.g. I independently initiate new individual or team projects and I manage and organize my time efficiently). The participants were asked to rank the extent to which they embodied each statement on a scale of one to four (1=rarely, $2=$ sometimes, $3=$ frequently and 4=almost always).

\section{Analysis Method}

Engineering Leadership Definition. For the purpose analyzing the definitions, qualitative content analysis methods were used, which can be defined as "qualitative data reduction and 
sense making"10. This methodology was chosen as it provided a systematic method to examine and make sense of the definitions of engineering leadership provided by participants.

Once the data was collected, the three phases of qualitative content analysis were followed: preparing, organizing and reporting ${ }^{11}$. During the preparation phase it was important to define the unit of analysis in order to consistently code the data. The unit of analysis was selected to be a single concept, which typically included a subject / a verb / the context (e.g. "leader / directs / a group of individuals"). Next, during the organizing phase the definitions were coded using this unit of analysis. Each of the 28 definitions were coded (ranging from 1-10 codes per definition), and the entire set of codes was compiled (total of 92 codes). Similar codes were grouped into headings, then reduced into main three themes and lastly abstracted to generate 14 categories. Finally the reporting phase involved, as it intuitively sounds, reporting on the findings.

Self-Rating of Leadership Skills. The data from the self-ratings were analyzed by determining the average rating given to each question based on the 37 responses. It is worthwhile to note that two questions included were phrased in the negative (e.g. I hesitate to make crucial decisions on project-related issues). The complement was thus determined for the analysis of these two questions.

\section{Results: Engineering Leadership Definition}

All of the definitions provided by the participants were transcribed for review. The definitions ranged in length from two words to 47 words, with an average length of about 16 words. Using the qualitative content analysis each definition was broken down into codes, or basic concepts. Similar codes were given headings, grouped together and three main themes were determined from the data: Strong Character, Team Dynamics and Technical. Table 2 lists these themes, as well as an additional six sub-themes. Participants' definitions that particularly emphasized each sub-theme are given as an example.

Table 2. Determined themes and sub-themes of the term engineering leadership.

\begin{tabular}{|c|c|c|}
\hline Themes & $\begin{array}{c}\text { Sub- } \\
\text { Themes }\end{array}$ & Example Participant Definitions \\
\hline \multirow{2}{*}{$\begin{array}{l}\text { Strong } \\
\text { Character }\end{array}$} & $\begin{array}{l}\text { Personal } \\
\text { Character }\end{array}$ & $\begin{array}{l}\text { "[...] set an example through responsible, } \\
\text { accountable, and ethical behaviour." }\end{array}$ \\
\hline & $\begin{array}{l}\text { Influential } \\
\text { Character }\end{array}$ & $\begin{array}{l}\text { "The ability to inspire trust and confidence in a group } \\
\text { of people." }\end{array}$ \\
\hline \multirow[b]{2}{*}{$\begin{array}{c}\text { Team } \\
\text { Dynamics }\end{array}$} & $\begin{array}{c}\text { Team } \\
\text { Leader }\end{array}$ & "Manage people, projects." \\
\hline & $\begin{array}{l}\text { Team } \\
\text { Work }\end{array}$ & $\begin{array}{l}\text { Engineering leadership "is particularly important due } \\
\text { to a group effort, }[\ldots] \text { know when to step up and allow } \\
\text { for others to do the same" }\end{array}$ \\
\hline \multirow[b]{2}{*}{ Technical } & Skills & "Problem-solving and communication." \\
\hline & $\begin{array}{l}\text { Problem } \\
\text { Types }\end{array}$ & $\begin{array}{l}\text { "[...] tackle complex social, developmental, and } \\
\text { global issues with confidence, courage, and humility." }\end{array}$ \\
\hline
\end{tabular}


The findings provide an understanding of engineering leadership from the perspective of undergraduate engineering students with an interest in leadership. The first two themes, Strong Character and Team Dynamics, are very general and could be applicable to a leader within any context. However, the third theme, Technical, is what truly differentiates a leader from an engineering leader. The technical theme included the following categories: analytical abilities, managing complexity, helping society, and technical communication. These categories are distinctive to the field of engineering.

Proportional frequencies of the themes within the total set of codes can be seen in Figure 1. Strong Character and Team Dynamics each included 35\% of the total codes, and Technical included $30 \%$. These similar proportions show that the three themes have almost an equivalent frequency within the definitions, indicating that the students give each one a similar level of emphasis. It is particularly notable that students view the importance of the general leadership skills equally to the technical competency of a leader in engineering.

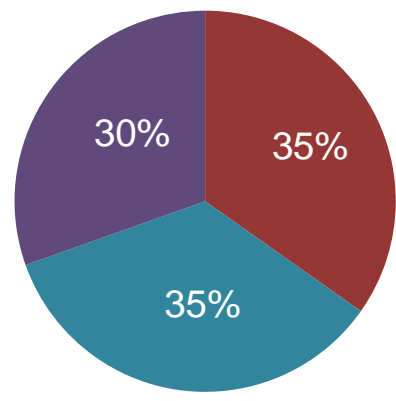

- Strong Character

- Team Dynamics

- Technical

Figure 1. Proportional frequency (emphasis) of engineering leadership themes.

After grouping the codes into the three main themes and six sub-themes, the data was abstracted to generate 14 categories. This abstraction process created smaller groupings within sub-themes of similar concepts. A visualization summarizing the themes, sub-themes, and categories is shown in Figure 2.

The top three themes and six sub-themes represent the components that were most prominent within the definitions, and the lower-level categories represent an idea within each sub-theme. Thus, the broad themes are the most essential, and the categories provide further detail. For example, it would be most important to teach students about having a Strong Character in general terms, and then discuss how this relates to their own individual Personal Character. The final most in-depth discussions would include the importance of being Accountable, Ethical and Taking Initiative.

The participant inclusion rate of each category was determined and is visualized in Figure 3. The highest inclusion rate was Manage Complex Issues (29\%, or 8 of 28), which included definitions such as "providing a vision and technical expertise." Again, this emphasizes the technical theme, highlighting the importance of engineering leaders having a strong technical background. Engineering leaders must demonstrate competency in their technical knowledge in order to demonstrate proficiency ${ }^{3}$ and to earn the trust of their team. 


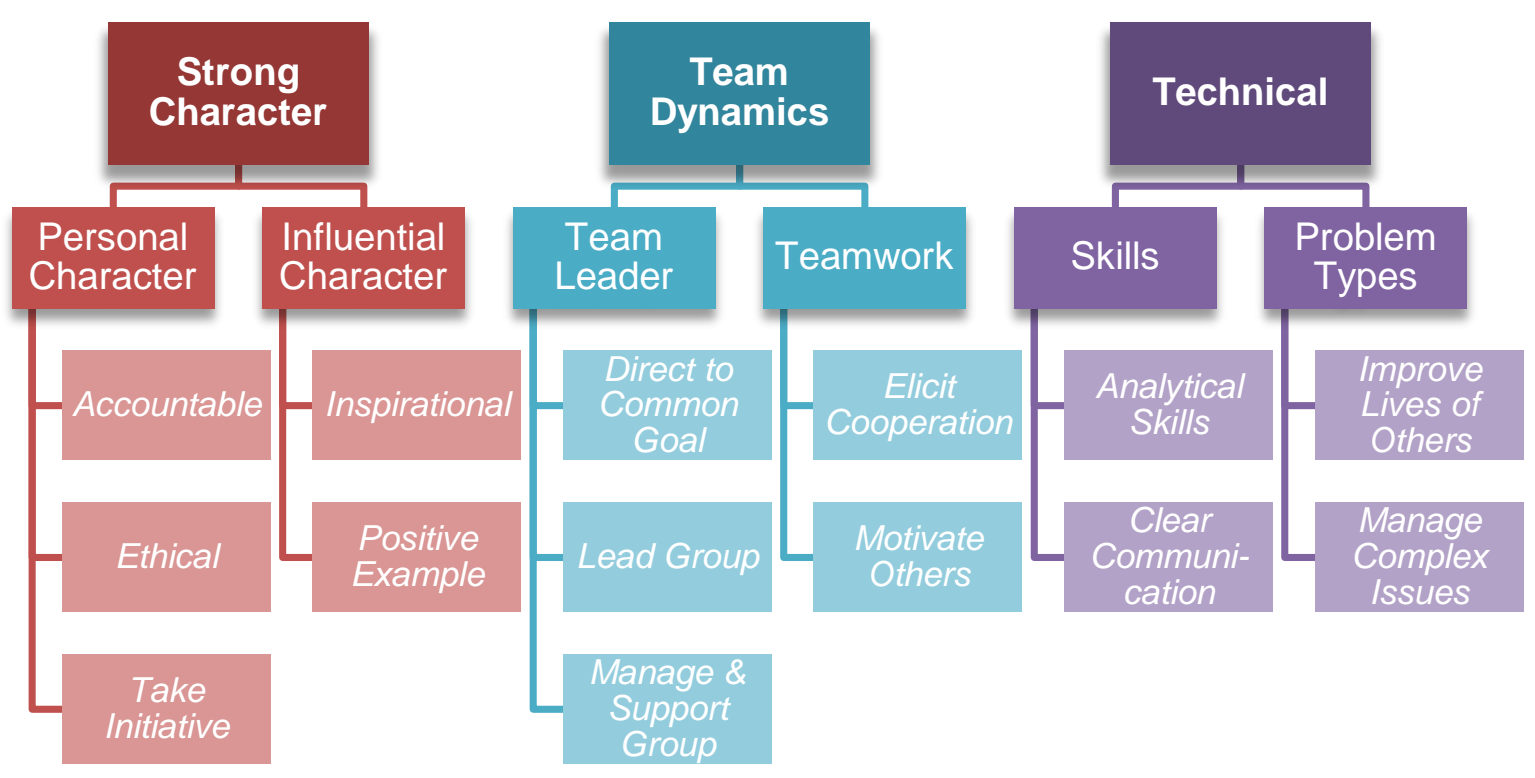

Figure 2. Visual representation of determined themes, sub-themes and categories of the term engineering leadership.

The categories with the lowest inclusion rates were Accountable and Analytical Skills (each $11 \%$, or 3 of 28). Although both of these are essential for engineering leadership, it is possible that students view them as general engineering skills that are not unique or specifically crucial for engineering leaders.

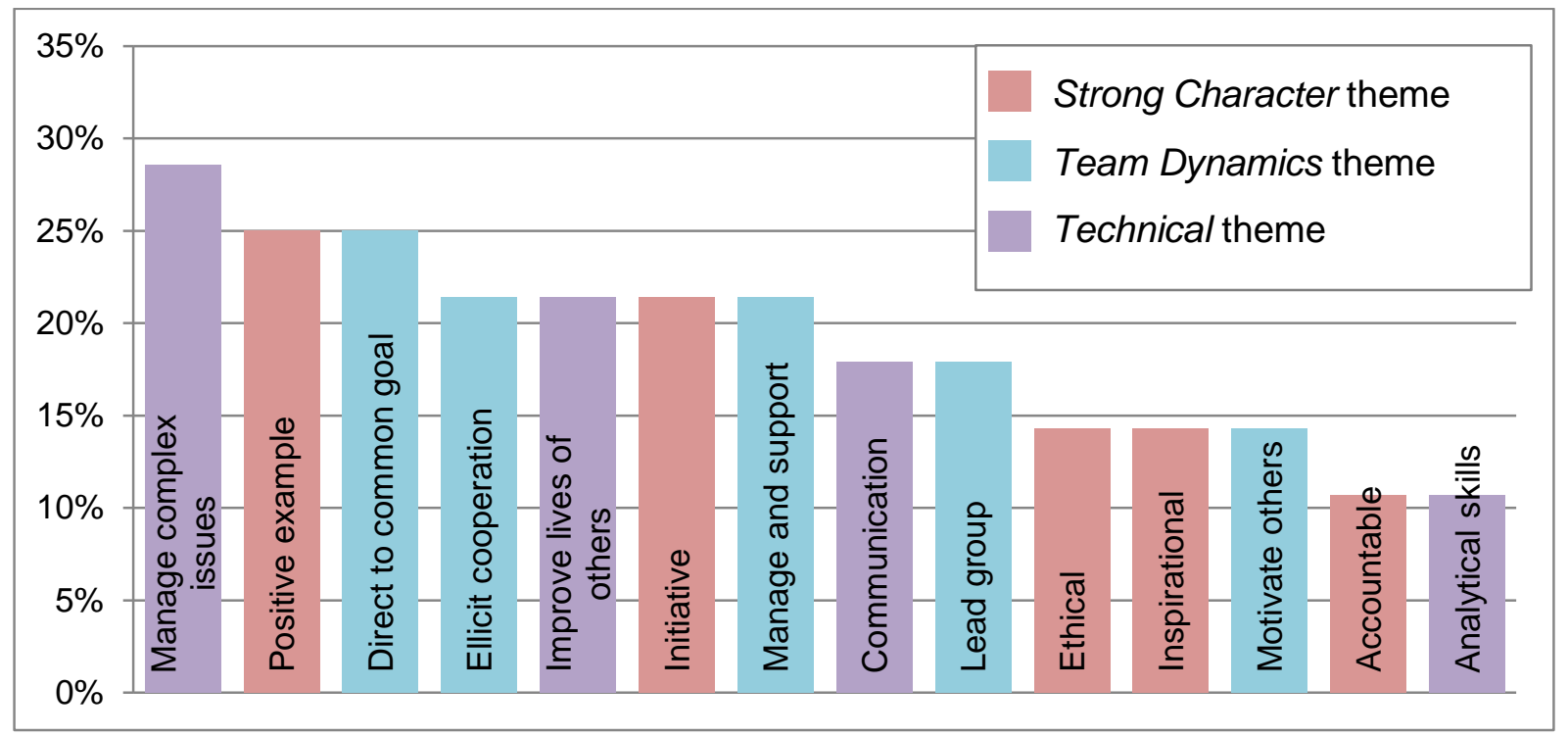

Figure 3. Inclusion rate of engineering leadership categories within participants' definitions. 
Comparison to Published Definitions. Definitions provided at the beginning of this paper covered many concepts, and specifically four general ideas expressed within these definitions are highlighted here.

1. Take action - lead change $\left(\mathrm{GEL}^{6}\right)$, make decisions $\left(\mathrm{NSPE}^{7}\right)$, invention $\left(\mathrm{GEL}^{6}, \mathrm{CDIO}^{8}\right)$

2. Manage uncertainty $\left(\mathrm{NSPE}^{7}, \mathrm{CDIO}^{8}\right)$

3. Teamwork - team $\left(\mathrm{NSPE}^{7}\right)$, facilitate $\left(\mathrm{CDIO}^{8}\right)$

4. Help others $\left(\mathrm{CDIO}^{8}\right)$ - trust and loyalty $\left(\mathrm{NSPE}^{7}\right)$

The latter two of these were well covered in the definitions provided by the students, however, the first two ideas were less prominent. The category Take Initiative relates to the first concept of taking action, however Take Initiative in the definitions typically emphasized stepping up, rather than getting things done by taking action. The concept of uncertainty could be indirectly related to the category Manage Complex Issues, however complexity and uncertainty are two very different concepts that must be managed independently within engineering projects.

Overall the students' perspective of engineering leadership is appropriate, however there are some key elements missing. Within the curriculum, it is essential to ensure students are able to learn and practice the full spectrum of engineering leadership. This includes understanding how to lead the process of conceiving, designing, implementing, and operating ${ }^{8}$ within an engineering context.

\section{Self-Rating of Engineering Leadership Skills}

The results from the engineering leadership skills questionnaire provided insight into the confidence that the students have of their own engineering leadership skills. The items from questionnaire were categorized into the sub-themes generated from the definition analysis. For example the question "I actively encourage my peers to solve problems" was placed in the sub-theme Teamwork. Each sub-theme mapped to four pertinent questions, except Influential Character mapping to three questions and Problem Types with only one applicable question.

After categorizing all of the questions into sub-themes, the average ratings were found for each sub-theme, summarized in Figure 4. The questions that student rates themselves higher in were questions related to Influential Character (average score of 3.4). This shows that the students were confident in the fact that they are able to make a difference in the world and that their actions can motivate and influence others.

The lowest rated questions included many questions related to technical skills, with the lowest sub-theme being Problem Types (average score of 2.8). Even though in the engineering leadership definition the students emphasized the importance of technical abilities, when rating themselves, they were less confident in this area. This underlines the importance of contextual leadership experience and the need for integrated learning experiences. The majority of survey participants were involved in a nontechnical leadership role, such as vicepresident on an engineering students' society. Although this is excellent experience, it does not provide students with a contextual engineering leadership experience. 
A 2009 paper reviewing over 40 engineering leadership programs determined that the majority of the programs taught leadership content outside the context of engineering ${ }^{12}$. The seventh CDIO Standard outlines the importance of teaching disciplinary knowledge simultaneously with personal and interpersonal skills ${ }^{8}$. The students must gain not only the skills of leadership, but understand how to apply these within an engineering context. The survey results show that when the leadership skills are taught separate from engineering, the students do not understand how to apply their skills in a technical context.

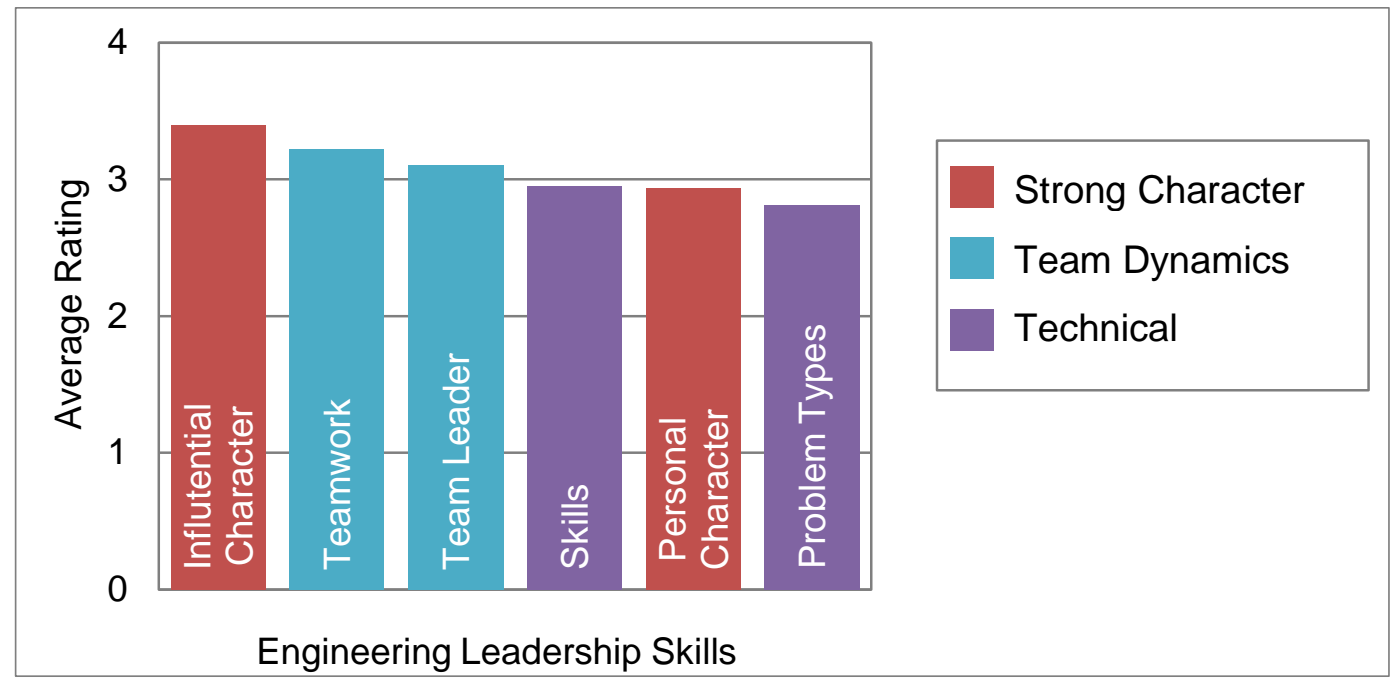

Figure 4. Averages of students' self-rating of their engineering leadership skills based on a $1-4$ scale (1=rarely, 2=sometimes, $3=$ frequently, $4=$ =almost always)

\section{Gender Perspectives on Engineering Leadership}

Research has shown that the gender gap within STEM careers, particularly in leadership positions, is not due to deficits in capacity but rather due to the negative influences and barriers that are encountered by women and minorities ${ }^{13}$. Comparison of the results from men to women will be important in gaining an understanding of the different perspectives on engineering leadership. To ensure inclusivity and diversity in the workplace, a balance between all the elements of engineering leadership education is required.

For this pilot study, a comparison was done between female and male participants. Previously, Figure 1 showed there was a relatively equivalent emphasis between the three generated themes. Here, Figure 5 highlights the gender differences in these proportional frequencies. Both males and females emphasized the Technical theme similarly with about one third of the codes. However, females tended to highlight the Teamwork them whereas males included a higher frequency of Strong Character within their definitions.

The results from the skills questionnaire show little difference between the genders (Figure 6). The largest variation is seen in Teamwork, where females tend to have a higher confidence in their teamwork skills. This is consistent with other research that has shown women typically assess their professional skills, including teamwork, higher than men ${ }^{14}$. Considering the small 
sample size, further data will need to be collected to provide a stronger understanding of the difference within the context of this research.

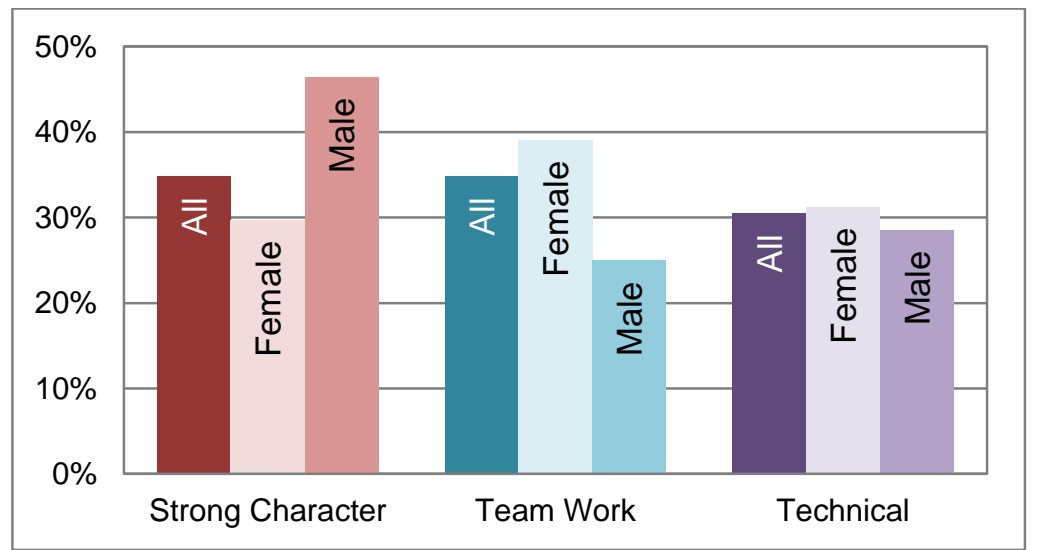

Figure 5. Proportional frequency (emphasis) of engineering leadership themes.

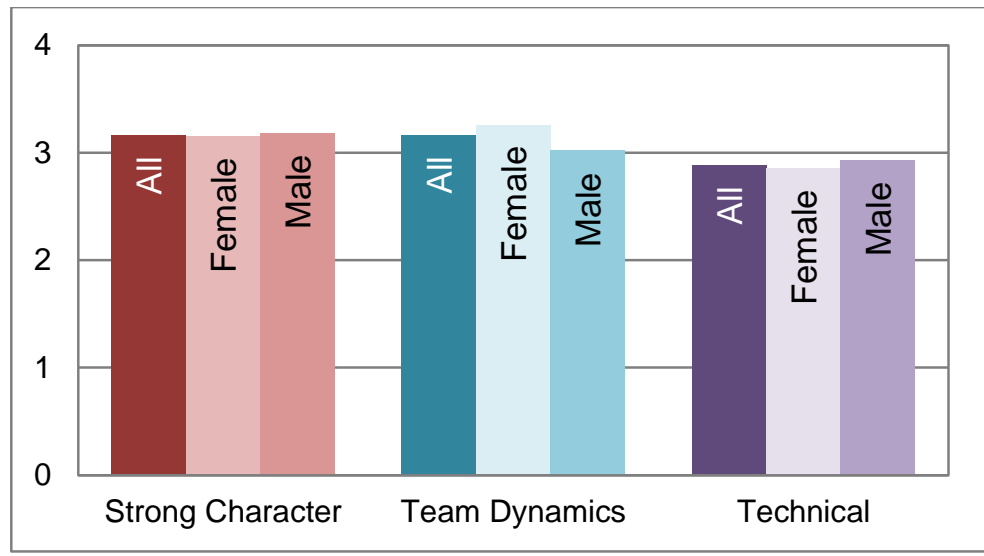

Figure 6. Averages of students' self-rating of their engineering leadership skills based on a $1-4$ scale (1=rarely, $2=$ sometimes, $3=$ frequently, $4=$ =almost always)

\section{Conclusion}

Engineering undergraduate students with an interest in leadership have a reasonable understanding of the term engineering leadership. A more complete and contextual engineering leadership experience would provide them with insight into an improved understanding. The results from the themes and categories generated from the students' definitions would be useful in developing and improving engineering leadership education programs

Students understood the importance of being technically competent as an engineering leader, however they had a lower confidence in their own technical leadership abilities. This gap emphasized the importance of integrated learning within the engineering curriculum. Providing students with integrated engineering leadership experiences directly within the 
technical curriculum would allow the necessary leadership skills to be gained concurrently with an understanding how these skills will apply to an engineering career.

\section{Future Directions}

The methods and results used in this pilot study will be applied to a variety of engineering populations including first-year students, fourth-year students, graduate students, professors and professionals. Each population's different perspective will be determined and compared in order to provide insight into what students think they need to know, what professors think they should teach, and what is actually desired from industry. A comparison of results from the different demographics will also provide valuable information, including the perspectives of men compared to women, of first year students compared to final year students, of varied cultural backgrounds, and of the different disciplines (e.g. chemical, electrical, mechanical).

The determined engineering leadership themes could be used to further investigate the importance placed on these different skills. Many studies have shown that industry desires new graduates to possess engineering leadership ${ }^{15}$, however a disconnect will occur if there is a lack of congruency between the industry perspective and the perspective of the students and professors.

In future surveys, participants will also be asked for their perspectives on the integration of leadership within a technical engineering context. Student participants will be asked for input on how their leadership skillset could be improved such that the technical application is better understood. Alumni participants will be asked on how they have successfully integrated their nontechnical leadership skills within their technical engineering career.

\section{REFERENCES}

[1] S. Kumar and J. K. Hsiao, "Engineers Learn 'Soft Skills the Hard Way': Planting a Seed of Leadership in Engineering Classes,” Leadership and Management in Engineering, vol. 7, no. 1, pp. 18-24, 2007.

[2] P. Galloway, "Engineering Education Reform," in The 21st-Century Engineer: A Proposal for Engineering Education Reform, American Society of Civil Engineers, 2007, pp. 46-51.

[3] B. Ahn, M. F. Cox, J. London, O. Cekic, and J. Zhu, "Creating an Instrument to Measure Leadership, Change, and Synthesis in Engineering Undergraduates,” Journal of Engineering Education, vol. 103, no. 1, pp. 115-136, Jan. 2014.

[4] S. S. K. W. Fakeh, M. S. Shahibi, A. Jamaludin, M. R. Rahim, J. Paiman, and Z. Ibrahim, "Understanding Leadership Values Among Under Graduate Students in UITM: Their Values, Beliefs, and Motivation," International Journal of Innovative Research in Computer Science and Tech., vol. 2, no. 3, pp. 1-6, 2014.

[5] E. F. Crawley, W. A. Lucas, J. Malmqvist, and D. R. Brodeur, “The CDIO Syllabus v2.0: An Updated Statement of Goals for Engineering Education," in International CDIO Conference, 2011.

[6] Gordon-MIT, “Capabilities of Effective Engineering Leadership,” Bernard M. Gordon-MIT Eng. Leadersh. Progr., no. 3.6, 2011. 
[7] NSPE, "NSPE Position Statement No . 1752 — Engineering Education Outcomes," National Society of Professional Engineers, 2010. [Online]. Available: http://www.nspe.org/sites/default/files/resources/GR downloadables/Engineering_Education_Outcomes.pdf. [Accessed: 01-Dec-2014].

[8] E. F. Crawley, J. Malmqvist, S. Östlund, D. R. Brodeur, and K. Edström, Rethinking Engineering Education: The CDIO Approach, 2nd Ed. Springer International Publishing, 2014.

[9] J. W. Creswell, Qualitative inquiry and research design: Choosing among five traditions. Thousand Oaks, CA: Sage, 1998.

[10] Y. Zhang and B. M. Wildemuth, "Qualitative Analysis of Content,” in Applications of Social Research Methods to Questions in Information and Library Science, Westport, CT: Libraries Unlimited, 2009, pp. 308-319.

[11] S. Elo and H. Kyngäs, "The qualitative content analysis process,” Journal of Advanced Nursing, vol. 62, no. 1, pp. 107-115, 2008.

[12] R. Graham, E. Crawley, B. R. Mendelsohn, W. Paper, B. M. Gordon, M. I. T. Engineering, and L. Program, "A snapshot review of international good practice," 2009.

[13] J. Dugan, K. Fath, S. Howes, K. Lavelle, and J. Polanin, "Developing the Leadership Capacity and Leader Efficay of College Women in Science, Technology, Engineering, and Math Fields," Journal of Leadership Studies, vol. 7, no. 3, 2013.

[14] H. Ro, and LK. Loya, "The Effect of Gender and Race Intersectionality on Student Learning Outcomes in Engineering," The Review of Higher Education, vol. 38, no. 3, Spring 2015.

[15] G. Hillmer, R. Wiedenbrueg, and a Bunz, "Chapter 26: Competences Required by Industry from EarlyCareer Engineering Graduates - Developing Management \& Leadership Skills in Engineering Education," Innovations, pp. 291-304, 2012. 